\title{
PEMBAGIAN PECAHAN TERINTEGRASI DENGAN KONSEP LAIN MELALUI PENDIDIKAN MATEMATIKA REALISTIK INDONESIA
}

\author{
Oleh: \\ 1) Muhamad Saleh, ${ }^{2)}$ Muhammad Isa \\ ${ }^{1,2)}$ FKIP Universitas Serambi Mekkah Banda Aceh \\ ${ }^{1}$ muhamadsalehginting@yahoo.com
}

\begin{abstract}
ABSTRAK
Hasil belajar pecahan diharapkan sesuai dengan tujuan yang telah di tetapkan. Kenyataannya siswa mengalami kesulitan menyelesaikan pecahan. Dalam menjalankan proses belajar guru harus mempertimbangkan tingkat kesiapan siswanya untuk mengikuti proses belajar. Upaya yang dilakukan adalah memilih pengetahuan siswa dari pengalaman belajarnya yang dapat dijadikan untuk menjembatani antara pengalaman belajarnya dengan materi baru, sehingga mereka lebih siap dalam mengikuti proses belajar selanjutnya. Diperlukan rancangan pembelajaran yang dapat dijadikan guru sebagai rujukan dalam melaksanakan pembelajaran. Pendekatan Pendidikan Matematika Realistik Indonesia (PMRI) dalam pembelajaran pembagian pecahan dapat diintegrasikan dengan materi/konsep lain.
\end{abstract}

Kata Kunci : realistik, pembagian pecahan, integrasi

\begin{abstract}
The result of learning fraction is expected suitable with the objectives that have been set. In fact the students have difficulties in completing fractionas. In carrying out the process of learning the teacher should consider the students readiness to follow the learning process. Efforts is to choose the knowledge of students from their learning experiences that can be used to bridge between learning experience with new material, so they are better prepared to follow the learning process further. Required learning design that can be used by teacher as a reference in implementing the learning. To implement the approach of Indonesian Realistic Mathematics Education (PMRI) in learning fractions can be integrated with the material / other concepts.
\end{abstract}

Keywords: realistics, division of fractions , integrated

\section{PENDAHULUAN}

Sulit dibayangkan bagaimana proses dan hasil belajar terhadap orang yang tidak memiliki kemampuan mendengar dan bertujuan untuk mengetahui merdunya suara kicauan burung. Secara tertulis mungkin mereka dapat memberikan jawaban, namun tidak mampu memahaminya bahkan bukan sebagai pengetahuan yang dimilikinya. Hal ini terjadi karena kondisinya yang tidak mendukung untuk mengetahui segala jenis suara. Demikian halnya guru sebagai pengajar sekaligus sebagai fasilitator 
perlu memperhatikan kondisi atau kemampuan dari siswanya yang terlibat dalam mendukung berlangsungnya proses belajar mengajar. Dukungan dari guru yang menggunakan pendekatan pembelajaran yang tepat dalam melaksanakan proses belajar matematika, dapat meningkatkan prestasi belajar siswanya melalui peningkatan kemampuan pemecahan masalah matematika.

Masih rendahnya prestasi belajar matematika di indonesia menjadi perhatian sekaligus menjadi tugas dan tanggung jawab bagi seluruh stakeholder termasuk didalamnya adalah bagaimana kemampuan guru dalam melaksanakan proses pembelajaran. Salah satu elemen yang terlibat langsung dalam instrumen pembelajaran matematika di Sekolah adalah para guru yang mengajar di sekolah. Namun tidak semata-mata bahwa guru sebagai satu-satunya yang memerlukan perhatian dalam meningkatkan prestasi belajar siswa di sekolah. Banyak faktor yang dapat mempengaruhi peningkatan prestasi belajar siswa. Guru, pendekatan pembelajaran, buku referensi belajar siswa termasuk dalam beberapa faktor tersebut. Untuk itu guru dan berbagai pendekatan pembelajaran perlu mendapat perhatian kita bersama dalam rangka meningkatkan prestasi belajar siswa.

Kurikulum 2013 merekomendasikan bahwa dalam melaksanakan pembelajaran matematika di awali dengan masalah kontekstual yang di jadikan sebagai tema pembelajaran. Masalah kontekstual/tema dalam kurikulum 2013 yang berlaku, berkatian dengan aktivitas manusia (human aktivity). Melalui konteks yang telah dapat dibayangkan oleh siswa, akan dapat membantu siswa memahami makna pembelajaran yang mereka hadapi. Disisi lain dalam melaksanakan pembelajaran yang mengandung masalah kontekstual, dapat melibatkan benda konkret. Melalui benda konkret dalam proses belajar matematika dapat menjadikan proses belajar akan memicu terjadinya aksi spontan dari siswa yang melibatkan beberapa indera dari siswa. Melalui benda konkret siswa dapat melihat, mengamati bahkan meraba benda konkret tersebut. Dengan demikian siswa menjadi aktif dalam melaksanakan proses pembelajaran, yaitu aktif secara fisik maupun aktif secara mental. Proses pembelajaran yang melibatkan banyak indera dapat menjadikan hasil pembelajaran yang mengakibatkan daya ingat siswa menjadi lebih lama, karena dalam proses pembelajaran, mereka mengalami secara langsung melalui benda-benda konkret yang merepresentasikan matematika.

Tidak selamanya belajar matematika dengan benda konkret. Tujuan digunakan konteks dan benda konkret agar mereka dapat terbantu "mengkonkretkan" materi matematika yang didominasi oleh materi yang abstrak. Benda konkret digunakan sebagai alat untuk merepresentasikan materi matematika yang abstrak dan berlangsung secara bertahap menuju pemahaman matematika secara formal dan abstrak, sehingga keabstrakan matematika dapat mereka pahami dan dapat mereka fikirkan secara konkret. Soedjadi mengatakan (1999/2000:7) bahwa :" keabstrakan objek-objek yang terdapat dalam matematika itu perlu diupayakan agar dapat diwujudkan secara lebih konkret, sehingga dapat membantu siswa lebih mudah 
memahaminya. Inilah kunci penting yang sebaiknya diketahui guru matematika, dan diharapkan dapat dijadikan pendorong untuk lebih kreatif dalam merencanakan pembelajaran.

\section{STUDI LITERATUR}

\section{Pembelajaran Realistik}

Sesuai dengan teori yang dikemukakan oleh Piaget, (Dahar, 1988:106) bahwa : "dari teori perkembangan Piaget kita mengetahui, bahwa anak-anak yang masih kecil baru dapat belajar konsep-konsep konkret, sedangkan konsep-konsep yang lebih sulit atau lebih abstrak dipelajari setelah mereka besar". Berdasarkan penelitiannya, Piaget mengemukakan empat tahap perkembangan kognitif dari setiap individu. Empat tahap secara kronologis menurut uisa pada manusia adalah sebagai berikut:

1. Tahap sensori motor, pada anak berusia dari 0 sampai usia 2 tahun

2. Tahap pra operasi, dari sekitar umur 2 tahun hingga sekitar umur 7 tahun

3. Tahap operasi konkret, dari sekitar umur 7 tahun sampai sekitar 11 tahun

4. Tahap operasi formal, dari sekitar umur 11 tahun dan seterusnya.

Kemudian Bruner, melalui teorinya mengungkapkan bahwa dalam proses belajar anak sebaiknya diberi kesempatan untuk memanipulasi benda-benda (konkret). Melalui benda konkret yang ditelitinya itu, anak akan melihat langsung bagaimana hukum-hukum yang berlaku dalam keterkaitan benda yang dia amati dan kaitannya dengan representasi matematika yang bersesuaian. Bruner mengemukakan, siswa melalui 3 tahap dalam proses belajarnya, yaitu:

1. Tahap enaktif

2. Tahap ikonik dan

3. Tahap simbolik

Atas pertimbangan dari teori yang diukemuakakan di atas, proses pembelajaran matematika perlu diawali dengan masalah kontekstual atau melibatkan benda konkret.

Realistic Mathematics Education (RME) salah satu pendekatan yang dapat di laksanakan oleh guru. Lahir dan berkembangnya Realistic Mathematics Education (RME) tidak terpisah dari Institut Freudenthal dibawah Utrecht University, Belanda. Nama Institut ini diambil dari nama yang memprakarsai berdirinya Institut Freudenthal, yaitu seorang guru besar Prof.Dr. Frans Freudental.

Sejak berdirinya pada tahun 1971, Institut Freudenthal mengembangkan suatu pendekatan pembelajaran, khususnya pada pendidikan matematika yang di sebut dengan Realistic Mathematics Education. RME telah mampu meningkatkan prestasi belajar matematika. RME bergerak dari pandangan bahwa matematika adalah human aktivities. Berdasarkan pandangan tersebut berarti, bahwa dalam kehidupan 
manusia selalu akan berkenaan dengan matematika. Pandangan ini akan menjadikan proses pembelajaran yang menghasilkan siswa yang memiliki kemampuan dalam menyelesaikan masalah matematika, baik dalam matematika itu sendiri maupun masalah dalam kehidupan sehari-hari. Dengan demikian ilmu dan pemahamannya terhadap matematika itu menjadi "miliknya" yang dapat digunakan.

Melalui proses pembelajaran yang tidak tepat, dapat menimbulkan pemahaman siswa secara mekanistik. Mungkin saja mereka dapat menyelesaikan masalah matematika, namun mereka tidak memahami apa yang mereka lakukan. Sering diberikan langkah-langkah dalam menyelesaikan masalah matematika khususnya pada materi penjumlahan pecahan. Algoritma-algoritma atau langkah-langkah yang di sampaikan ke siswa dalam menyelesaikan penjumlahan dua pecahan yang memiliki penyebut berbeda.

Langkah-langkah yang diberikan guru adalah sebagai berikut: 1. Samakan kedua penyebut pecahan, 2. Tambahkan pembilang dari kedua pecahan kemudian, 3. Hasil penjumlahan kedua pembilang dibagikan dengan penyebutnya. Berdasarkan instruksi yang dipahamin, siswa dapat menyelesaikan masalah penjumlahan dua pecahan yang berpenyebut berbeda sehingga mendapatkan skor yang maksimal. Namun secara konsep mereka tidak memahami apa yang mereka lakukan. Ada beberapa pertanyaan yang dapat di ajukan berhubungan dengan jawaban yang diberikan siswa, untuk apa disamakan penyebutnya...? mengapa kedua pembilang pecahan ditambahkan dan kedua penyebutnya tidak ditambahkan.

Di Indonesia, istilah Realistic Mathematics Education (RME) dikenal dengan istilah Pendidikan Matematika Realsitik Indonesia (PMRI). Dua komponen yang penting dalam pendidikan matematika, yaitu matematisasi horizontal dan matematisasi vertikal. Kedua komponen ini terdapat dalam pembelajaran realistik. Matematisasi horizontal adalah proses transformasi dari masalah kontekstual ke dalam bentuk/simbol matematika, dan matematisasi vertikal adalah proses yang berlangsung dalam matematika yang menggunakan tahapan-tahapan yang baku pada matematika itu sendiri. Gravemeijer mengatakan bahwa : horizobtal mathematization stands for transforming a problem field into mathematical problem, and vertical mathematization for processing within the mathematical system (Gravemeijer, 1994).

Lima karakter yang terdapat dalam penerapan pembelajaran RME yang dikemukakan oleh Treffers, yaitu:

1. Menggunakan konteks

2. Menggunakan model

3. Menggunakan kontribusi siswa

4. Adanya proses interaktif dan

5. Menggunakan keterkaitan (intertwin). 
Salah satu dari karakter yang disebutkan di atas adalah menggunakan keterkaitan (intertwin). Melalui keterkaitan yang terdapat dalam pembelajaran RME akan memberikan kontribusi yang positif pada materi-materi lain. Baik secara langsung maupun secara tidak langsung, proses pembelajaran akan berdampak postif dalam memahami materi lain, baik di luar matematika maupun di dalam matematika itu sendiri.

Tidak mudah bagi siswa dalam memahami masalah dan konsep pecahan. Beberapa laporan yang berhubungan dengan kesulitan matematika terutama pecahan menyampaikan/ menunjukkan bahwa materi pecahan merupakan materi yang dianggap sulit oleh siswa. Shelby P. Morge (2011), melaporkan: " The topic of fractions can be intimidating and difficult for children, even into the middle grades. Demikian halnya yang disampaikan oleh Robert M. Capraro, dkk (2004):" Fractions are often difficult for students to fully comprehend. Teachers must find a variety of strategies to use in the classroom for teaching fractions.

Berdasarkan laporan yang disampaikan oleh Shelby $\mathrm{P}$ Morge dan Robert M. Capraro, bahwa materi pecahan tidak sekedar sebagai materi yang sulit bagi siswa, namun dapat menjadi suatu materi yang sulit dan sekaligus materi yang dapat mengintimidasi siswa. Disisi lain Yeping Li dan Dennie Smith (2007) melaporkan tentang empat hal penting yang berhubungan dengan kesulitan terhadap pecahan, termasuk kesulitan yang dialami oleh guru dalam melaksanakan pembelajaran pecahan: dalam melibatkan masalah dengan persyaratan konseptual dan masalah yang melibatkan banyak-langkah (disertai contoh masalah):

1) Bahwa pembagian pecahan itu sulit, bukan hanya bagi siswa SMP saja (Carpenter et al., 1988) melainkan juga bagi Calon Guru (Ball, 1990; Simon, 1993). Secara matematik pembagian pecahan dapat disampaikan dan dapat dipelajari dengan mudah sebagai "kebalikan dan perkalian". Bagaimanapun juga untuk menjelaskan konsep itu sangat sulit, artinya butuh penjelasan dengan menghubungkan antar satu pengetahuan dengan pengetahuan yang lain, misalnya dengan cara dihubungkan dalam kehidupan sehari-hari (Greer, 1992; Ma, 1999)".

2) Berdasarkan temuan dari studi pada pengetahuan dan kesulitan guru dengan materi pembagian dan pembagian pecahan, dapat dirangkum bahwa guru sering mengalami beberapa tipe-tipe kesulitan berikut.

- Bagaimana menjelaskan prosedur komputasi untuk "pembagian pecahan" dengan representasi yang berbeda.

- Bagaimana menjelaskan kenapa "kebalikan dan perkalian"

- Hubungan matematik antara pembagian pecahan dan kemampuan matematik lainnya, seperti konsep pembagian, penjumlahan, pengurangan, perkalian dari pecahan. 
- Kesalahan-kesalahan lainnya yang berhubungan, misalnya tidak dapat membagi bilangan yang kecil oleh bilangan yang besar, pembagian selalu membuat bilangan menjadi lebih kecil (e.g., Greer, 1992).

- Menyelesaikan masalah dengan menyertakan pembagian pecahan (e.g., Greer, 1992).

Identifikasi dari lima jenis kesalahan ini memberikan kerangka umum untuk penelitian terkini dan menyediakan garis besar untuk mengevaluasi kemungkinan-kemungkinan dari beberapa kesulitan calon guru SMP pada pembagian pecahan.

3) Hasil penelitian ini menunjukkan calon guru melakukannya dengan sangat baik dalam komputasi pembagian pecahan. Sebagai contoh, pada permasalahan "Temukan nilai dari 7/9:2/3", 93\% perserta memecahkan masalah dengan benar. Namun, ketika masalahnya dirubah sedikit dengan persyaratan konseptual, kinerja mereka menurun. Sebagai contoh, temukan "Ada berapa banyak $1 / 2$ di dalam 1/3?", hanya 52\% menjawab dengan benar. Banyak yang memberikan jawaban "tidak ada" atau "nol". Bahkan, masalah ini merupakan masalah yang ada dalam buku teks matematika siswa SMP.

4) Selain itu, calon guru ini mengalami kesulitan dalam memecahkan masalah yang melibatkan pembagian pecahan, terutama untuk beberapa masalah yang melibatkan banyak-langkah. Sebagai contoh, 39\% memcahkan masalah berikut dengan benar.

Johnny Pizza Ekspres menjual pizza dengan beberapa rasa. Suatu hari, terjual 24 pizza paperoni ukuran besar. Banyaknya pizza keju ukuran besar yang terjual pada hari itu $3 / 4$ dari banyaknya pizza paperoni ukuran besar yang terjual dan 2/3 dari banyaknya pizza spesial ukuran besar yang terjual. Berapa banyak pizza spesial ukuran besar yang telah dijual Pizza Expres pada hari itu?

Para calon guru juga menanyakan bagaimana memberikan penjelasan komputasi pembagian pecahan. Secara khusus, masalah "Bagaimana kamu akan menjelaskan kepada siswa mengapa $2 / 3: 2=1 / 3$ ? Mengapa $2 / 3: 1 / 6=$ 4" (diadaptasi dari Tirosh, 2000) dimasukkan dalam tes. Ditemukan bahwa $26 \%$ peserta menggambarkan dan menggunakan representasi piktorial (seperti: diagram pecahan, diagram pie) untuk menjelaskan prosedur pembagian dan $22 \%$ menjelaskan dengan "membalikan pecahan dan mengalikannya". Kebanyakan $46 \%$ peserta yang lainnya gagal untuk memberikan penjelasan yang lengkap dari semua komputasi. Peneliti juga tercengang, bahwa tidak ada calon guru yang mencoba menjelaskana komputasinya itu bagaimana bisa dengan cara "membalikan pecahan dan mengalikannya" (Seperti: mengapa kamu dapat merubah bentuk $2 / 3: 2$ ke dalam bentuk $2 / 3 \times 1 / 2$ ).

\section{Pembelajaran Pembagian Pecahan yang Terintegrasi}

Terdapat 5 interpretasi terhadap pecahan, yaitu :

1). Bagian dari keseluruhan

2). Pembagian 
3). Perbandingan

4).Operator dan

5). Pengukuran

Interpretasi dari kelima pecahan di atas sangat bergantung kepada konteksnya.

Pecahan merupakan materi baru yang dihadapkan dan diterima siswa sejak mereka memasuki sekolah dan belajar matematika formal. Untuk itu perlu dipikirkan pintu masuk belajar pecahan sehingga tidak terjadi lompatan yang di rasakan oleh siswa. Pintu masuk juga berfungsi untuk menjembatani materi yang telah dipahami oleh siswa dari pengalaman belajarnya sebelum memasuki belajar pecahan.

Beberapa konsep matematika dapat dijadikan untuk menjembatani materi yang telah biasa di hadapi oleh siswa dengan materi baru (pecahan). Makna dan konsep "lebih dari" dan "kurang dari" dapat dijadikan sebagai jembatan untuk memulai mereka belajar pecahan. "Lebih dari" dan "kurang dari" telah biasa mereka gunakan dalam keluarga dan dalam kehidupan sehari-hari, termasuk materi yang telah mereka dapatkan di bangku sekolah pendidikan formal. Mereka telah memahami konsep bahwa 3 lebih dari 2. Walaupun diapahami dengan bantuan benda konkret, termasuk benda-benda yang mereka gunakan dalam bermain seperti kelereng, gambar, besaran uang dll. Melalui konsep "lebih dari" dan "kurang dari", dapat digunakan sebagai konsep awal untuk mengarahkannya untuk menemukan konsep pecahan "setengah". Melalui pemahaman "setengah" selanjutnya diberikan pecahan yang melambangkan "setengah" yaitu " $1 / 2$ ". Melalui pemahaman mereka tentang $1 / 2$, berikutnya di bimbing untuk mereka dapat menemukan makna atau konsep pecahan yang lebih kompleks dan sederhana yaitu pecahan yang memiliki pembilang lebih dari satu, misalnya $2 / 3,3 / 4$ dan seterusnya.

Pemahaman mereka tentang konsep pecahan, dimanfaatkan untuk proses pembelajaran pembagian pecahan dengan bentuk: 1). Pembagian bilangan asli dengan pecahan, 2. Pembagian pecahan dengan pecahan.

Contoh: masalah pembagian bilangan asli dengan pecahan dan di kaitkan dengan aritmatika sosial:

\section{Tentukan hasil pembagiannya: $2: 1 / 5=\ldots$.}

Pembelajaran yang dapat dilakukan berkaitan dengan pembagian ini adalah melalui masalah kontekstual yang dapat di kaitkan dengan materi/konsep lain, sebagai berikut:

Pak tani memiliki sebidang tanah yang ingin ditanami singkong. Lahan tersebut ingin ditanami singkong seluruhnya. Setiap potongan batang singkong yang ingin di tanam berukuran panjang $1 / 5 \mathrm{~m}$. Pak Tani membeli setiap batang singkong berukuran $2 \mathrm{~m}$ dengan harga Rp. 200,00. Lahan pak 
tani berukuran persegi panjang dengan ukuran 10m x 20m. Jarak satu pohon dengan pohon yang lain adalah $1 / 2 \mathrm{~m}$. Batang singkong di tanam di dalam lahan pak tani dengan jarak $1 / 2 \mathrm{~m}$ dari batas tanah dan ditanam sejajar dengan dengan batas tanah.

$20 \mathrm{~m}$

Gbr: Lahan Pak Tani

a. Satu batang singkong berukuran $2 \mathrm{~m}$. Setiap bantang singkong dapat di bagi menjadi berapa potongan yang berukuran $1 / 5 \mathrm{~m}$....?

b. Berapa batang singkong yang berukuran panjangkah diperlukan Pak Tani sehingga semua lahannya tertanami dengan singkong...?

c. Berapa biaya yang diperlukan pak tani untuk membeli seluruh batang singkong sehingga semua lahannya tertanami dengan singkong....?

Melalui masalah kontekstual yang diajukan kepada siswa yang terintegrasi dengan aritmatika sosial, akan memberikan efek positif dalam pembelajaran, terutama terhadap muatan pembelajaran yang lebih luas. Secara tidak langsung, proses pembelajaran pembagian pecahan telah memuat materi aritmatika sosial.

Dalam proses pembelajaran pecahan, perlu diperhatikan dan dipikirkan kata yang tepat sehingga tidak menimbulkan makna yang berbeda antara yang dimaknai oleh guru dengan pemaknaan yang diberikan oleh siswa. Hati-hati dengan penggunaan "bagian" pada saat mengajukan masalah tertulis tentang pecahan. Dapat saja mereka memberi makna "bagian" adalah merupakan satu unit. Misalnya ketika ada masalah yang di ajukan kepada siswa:

Berapa bagiankah daerah yang berwarna merah?... Berdasarkan gambar yang diberikan maka mereka mungkin memberikan jawaban adalah dua bagian, padahal yang dipikirkan atau yang diharapkan jawaban yang diberikan oleh siswa adalah $2 / 3$ bagian dari seluruh (satuan unit) yang ada.

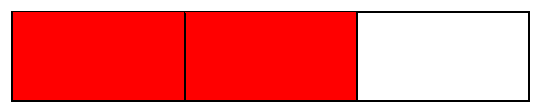

Agar tidak terjadi kesalah pahaman dalam memaknai masalah yang diajukan, guru perlu memberikan bimbingan kepada siswa sehingga pemaknaan 'bagian' dipahami dengan tepat dan tidak menimbulkan pemaknaan berbeda. Pemaknaan yang berbeda akan menimbulkan hasil yang bebeda pula. 
Lima interpretasi dari pecahan yang telah disampaikan di atas dan disepakati oleh peneliti bidang pendididikan yang disampaikan oleh Shelby P. Morge ( 2011) sebagai berikut: Education researchers have agreed upon five main interpretations of fractions: part of a whole or set, division, ratio, operators, and measurement (Behr, Harel, Post, \& Lesh, 1992; Chapin \& Johnson, 2006; Kieren, 1988; Lamon, 1999; Van de Walle, Karp, \& Bay-Williams, 2010).

Sebagai ilustrasi dari 5 interpretasi/penafsiran utama dari pecahan tersebut, yaitu:

1. Bagian dari keseluruhan: ini 1 , kemudain sepertiganya ini

2. Pembagian: membagi 12 potong kue kepada 5 orang $=12 / 5$

3. Rasio: perbandingan antara dua kuantitas: 7 bola kuning dalam kumpulan bola yang berjumlah 30, maka perbandingan jumlah bola kuning dengan seluruhnya adalah 7:30

4. Operator: $2 / 5 \times 15$

5. Pengukuran: berapa banyak: $2: 1 / 3=6$

Interpretasi akhir tentang pecahan menyangkut pengukuran pecahan boleh jadi jarak pada garis bilangan atau panjangnya. Speghati yang mentah dapat di potong-potong kedalam potongan yang lebih kecil, mungkin sepertiga, dan 1/3 itu digunakan untuk mengukur (menentukan panjang) dari dua potongan spagheti secara keseluruhan. Perbedaan pengukuran dan bagian dari keseluruhan terletak pada: pengukuran melihat keseluruhannya sedangkan bagian dari keseluruhan melihat bagiannya.

\section{PENUTUP}

Matematika didominasi oleh materi yang abstrak. Anak yang duduk di kelas 4 Sekolah Dasar, rata-rata berumur sekitar 9-10 tahun. Berdasarkan tahap perkembangan kognitifnya berada pada operasi konkret. Untuk itu perlu upaya sehingga proses dan pendekatan yang digunakan dalam pembelajaran berdasarkan konteks yang telah di pahami oleh siswa dan jika diperlukan menggunakan benda konkret untuk melakukan operasi konkret sebagai jembatan dalam tahapan belajar siswa sesuai dengan tahapan materi serta sesuai pula dengan tahapan kematangan pemikiran siswa. Penerapan pembelajaran realistik dilakukan agar "Pengalaman awal siswa memanipulasi benda-benda fisik menjadi dasar untuk nanti belajar konseptual, Skemp (dalam Arla Westenskow, 2012)”.

Salah satu karakter belajar dengan pendekatan realistik menuntut adanya keterkaitan dengan materi/konsep lain bahkan dengan pelajaran lain (intertwin) jika memungkinkan. Proses pembelajaran pembagian pecahan dapat di integrasikan dengan aritmatika dan ukuran panjang.

Masih diperlukan bahan ajar realistik yang dapat di gunakan oleh guru dalam melaksanakan proses pembelajaran. Dengan tersedianya bahan ajar yang memadai 
dan praktis (dilengkapi dengan petunjuk penggunaan), akan bermanfaat bagi para guru-guru, terutama yang berada pada daerah yang "terisolir".

\section{DAFTAR PUSTAKA}

Arla Westenskow. (2012). Equivalent Fraction Learning Trajectories for Students with Mathematical Learning Difficulties When Using Manipulatives, Disertasi. Utah State University Digital Commons@USU. Logan, Utah.

Capraro, Robert M., Emilie A. Naiser, and Wendy E. Wright. "Teaching fractions: strategies used for tea ching fractions to middle grades students." Journal of Research in Childhood Education 18.3 (2004): 193+. Gale Education, Religion and Humanities Lite Package. Web. 29 Oct. 2013.http://go.galegroup.com/ps/i.do?id=GALE\%7CA116669570\&v=2.1\&u= $\mathrm{kpt} 01029 \& \mathrm{it}=\mathrm{r} \& \mathrm{p}=\mathrm{GPS} \& \mathrm{sw}=\mathrm{w} \& \mathrm{asid}=$ fafaf $1 \mathrm{dfcca} 89 \mathrm{ff0deb} 75 \mathrm{~b} 6670 \mathrm{e} 5 \mathrm{c} 27 \mathrm{~b}$.

Dahar, R.W. (1988). Teori-teori Belajar. Dirjen Dikti, Proyek Pengembangan Lembaga Pendidikan, Tenaga Kependidikan Jakarta.

Gravemeijer, K. (1994). Developing Realistic Mathematics Education, Utrech: Fruedenthal Institute.

Morge, Shelby P. (2011). "Helping children understand fraction concepts using various contexts and interpretations." Childhood Education 87.4 : 282+. Gale Education, Religion and Humanities Lite Package. Web. 29 Oct. 2013.http://go.galegroup.com/ps/i.do?id=GALE\%7CA254482618\&v=2.1\&u= $\mathrm{kpt} 01029 \& \mathrm{it}=\mathrm{r} \& \mathrm{p}=\mathrm{GPS} \& \mathrm{sw}=\mathrm{w} \& \mathrm{asid}=60 \mathrm{eec} 8 \mathrm{a} 022554 \mathrm{eb} 3 \mathrm{a} 85 \mathrm{faddec} 1 \mathrm{edea} 12$

Soedjadi. (1999/2000). Kiat Pendidikan Matematika di Indonesia. Konstatasi Keadaan Masa Kini Menuju Harapan Masa Depan. Direktorat Jenderal Pendidikan Tinggi. Jakarta:Depdiknas.

Yeping Li and Dennie Smith (2007). Prospective Middle School Teachers' Knowledge In Mathematics And Pedagogy For Teaching - The Case Of Fraction Division. In Woo, J. H., Lew, H. C., Park, K. S. \& Seo, D. Y Eds.). Proceedings of the 31st Conference of the International Group for the Psychology of Mathematics Education, Vol. 3, pp. 185-192. Seoul: PME. Texas A\&M University, U.S.A. http://www.emis.de/proceedings/PME31/3/185.pdf 